\title{
Comparison of the rheological properties of four root canal sealers
}

\author{
Seok Woo Chang ${ }^{1}$, Young-Kyu Lee ${ }^{2}$, Qiang Zhu ${ }^{3}$, Won Jun Shon ${ }^{4}$, Woo Cheol Lee ${ }^{4}$, Kee Yeon Kum ${ }^{4}$, Seung \\ Ho Baek ${ }^{4}$, In Bog Lee ${ }^{4}$, Bum-Soon Lim ${ }^{5}$ and Kwang Shik Bae ${ }^{4}$
}

The flowability of a root canal sealer is clinically important because it improves the penetration of the sealer into the complex root canal system. The purpose of this study was to compare the flowabilities of four root canal sealers, measured using the simple press method (ISO 6876), and their viscosities, measured using a strain-controlled rheometer. A newly developed, calcium phosphate-based root canal sealer (Capseal) and three commercial root canal sealers (AH Plus, Sealapex and Pulp Canal Sealer EWT) were used in this study. The flowabilities of the four root canal sealers were measured using the simple press method $(n=5)$ and their viscosities were measured using a strain-controlled rheometer $(n=5)$. The correlation between these two values was statistically analysed using Spearman's correlation test. The flow diameters and the viscosities of the root canal sealers were strongly negatively correlated $(\rho=-0.8618)$. The viscosity of Pulp Canal Sealer EWT was the lowest and increased in the following order: AH Plus $<$ Sealapex $<$ Capseal $(P<0.05)$. All of the tested root canal sealers showed characteristic time- and temperature-dependent changes in their rheological properties. The viscosities measured using the strain-controlled rheometer were more precise than the flowabilities measured using the simple press method, suggesting that the rheometer can accurately measure the rheological properties of root canal sealers.

International Journal of Oral Science (2014) 7, 56-61; doi:10.1038/ijos.2014.33; published 25 July 2014

Keywords: Capseal; rheological property; root canal sealer; strain-controlled rheometer

\section{INTRODUCTION}

The fluid- and bacteria-tight seal of a thoroughly cleaned and shaped root canal system is fundamental for endodontic treatment. ${ }^{1-3}$ An adequate seal of the root canal system cannot be achieved without a root canal sealer because gutta percha cannot bond to the dentinal walls. ${ }^{4}$ Moreover, the area that cannot be reached by gutta percha can be penetrated and sealed with a root canal sealer. ${ }^{5}$ An ideal root canal sealer should have good biocompatibility, ${ }^{6}$ antibacterial activity, ${ }^{7}$ good sealing ability ${ }^{4}$ and adequate flowability, ${ }^{8-9}$ which is clinically important to allow deep penetration of the narrow and complex anatomical spaces in root canal systems. In this regard, a precise investigation of the flowabilities of root canal sealers is important for evaluating their clinical performance.

However, few studies have examined the viscosity of root canal sealers. ${ }^{10-19}$ The majority of previous studies measuring the flowabilities of root canal sealers ${ }^{10-17}$ used the simple press method that is specified by the International Organization for Standardization (ISO) $6876 .^{20}$ Although this method is simple and economical, ${ }^{18}$ the information obtained is limited in that this method can determine only the compressed sealer diameter. In contrast, a strain-controlled rheometer provides information regarding the rheological properties of root canal sealers as a function of time and temperature. However, few studies have investigated the rheological properties of root canal sealers using a strain-controlled rheometer. ${ }^{18}$

The rheological properties of root canal sealers change with time because all root canal sealers undergo a setting reaction. ${ }^{21}$ Not all root canal sealers undergo identical patterns of change because each is affected by a different setting process (development of chemical crosslinks between the polymer chains). ${ }^{22}$

The rheological properties of root canal sealers also change with increasing temperature. ${ }^{19}$ In modern endodontic treatments, the continuous wave of condensation technique is widely used, in which gutta percha and the root canal sealer are exposed to a temperature of $\sim 200{ }^{\circ} \mathrm{C}$. However, no other study has investigated the changes in the rheological properties of root canal sealers that have been heated to $200{ }^{\circ} \mathrm{C}$.

Capseal is a newly developed root canal sealer that is composed mainly of calcium phosphate and calcium silicate. ${ }^{23}$ Previous studies of Capseal showed that this new root canal sealer has good sealing ability $^{24}$ and superior biocompatibility ${ }^{25}$ and that it promotes hard tissue formation. ${ }^{26}$

The purpose of this study was to compare the flowabilities measured using the simple press method and the viscosities of four root canal sealers (AH Plus, Capseal, Sealapex and Pulp Canal Sealer EWT) measured using a strain-controlled rheometer. The time- and

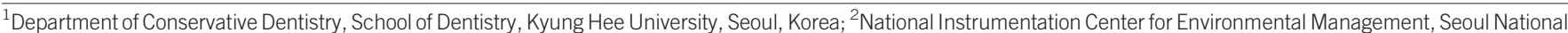

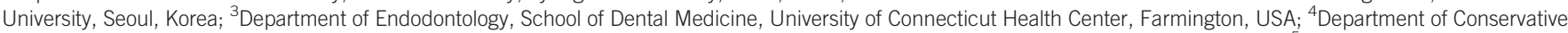

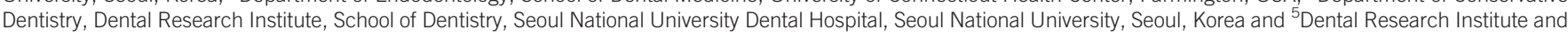
Department of Dental Biomaterials, School of Dentistry, Seoul National University, Seoul, Korea

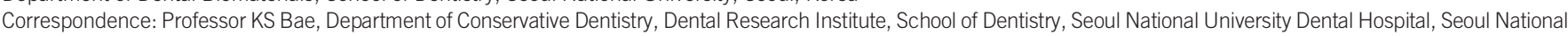
University, 28 Yungun-dong, Chongro-gu, Seoul 110-749, Korea
}

E-mail: baeks@snu.ac.kr

Accepted 28 April 2014 
temperature-dependent changes in the rheological properties of the root canal sealers were also investigated. The null hypothesis was that there was no correlation between the flowabilities measured using the simple press method and the viscosities measured using a strain-controlled rheometer.

\section{MATERIALS AND METHODS}

The materials used in this study were AH plus (Dentsply, Johnson City, TN, USA), Capseal (an experimental root canal sealer), Pulp Canal Sealer EWT (Sybron Endo, Orange, CA, USA) and Sealapex (Sybron Endo, Orange, CA, USA). The constituents of each material are listed in Table 1.

\section{Flowability measurement by the simple press method}

As described by ISO 6876, each root canal sealer $(0.05 \mathrm{~mL})$ was mixed according the manufacturer's instructions and placed on the centre of a glass plate (Hanil Dental, Goyang, Korea) The powder-to-liquid ratio recommended by the manufacturer was used when mixing AH Plus, Pulp Canal Sealer EWT, and Sealapex. The powder-to-liquid ratio for Capseal was $1: 1.5(\mathrm{~m} / \mathrm{m})$. At $180 \mathrm{~s}$ after initiating mixing, another glass plate was placed centrally on top of the sealer, followed by a weight, for a total mass of $120 \mathrm{~g}$. Using this procedure, the mixed sealers were compressed between the two glass plates and formed disc shapes. Ten minutes after initiating mixing, the weight was removed and the diameters of the compressed sealer discs were measured. Five samples were prepared for each sealer, and the diameters were measured for all samples.

\section{Viscosity measurement using a strain-controlled rheometer}

The root canal sealers were placed under oscillatory shear strain and sinusoidally deformed to measure viscoelasticity ${ }^{27}$ using a strain-controlled rheometer (ARES, Rheometric Scientific, London, UK).

\section{Theory of viscoelasticity in a dynamic oscillatory shear test}

When a material is purely elastic, the strain and stress are in phase, and the phase shift $\delta=0$. If a material is purely viscous, the stress and strain are $90^{\circ}$ out of phase $(\delta=90)$ (ref.27) (Figure 1). Because all root canal sealers have both viscous and elastic properties, the $\delta$ value for root canal sealers is between $0^{\circ}$ and $90^{\circ}$.

\section{Table 1 The materials used in this study}

\begin{tabular}{|c|c|}
\hline Products & Composition \\
\hline \multicolumn{2}{|l|}{$\mathrm{AH}$ plus } \\
\hline Epoxide paste & Diepoxide, calcium tungstate, zirconium oxide, aerosil, pigment \\
\hline Amine paste & $\begin{array}{l}\text { 1-adamantane amine, N,N'-dibenzyl-5-oxa-nonandiamine-1,9, } \\
\text { tricyclodecane-diamine, calcium tungstate, zirconium oxide, aerosil, } \\
\text { silicone oil }\end{array}$ \\
\hline \multicolumn{2}{|l|}{ Capseal } \\
\hline Powder & $\begin{array}{l}\text { Tetracalcium phosphate and dicalcium phosphate dehydrate, } \\
\text { calcium silicate, zirconium oxide, others }\end{array}$ \\
\hline Liquid & Hydroxypropyl methyl cellulose in sodium phosphate solution \\
\hline \multicolumn{2}{|l|}{ Pulp Canal } \\
\hline \multicolumn{2}{|l|}{ Sealer EWT } \\
\hline Powder & Zinc oxide, silver powder, thymol iodide, dimeric acid resin \\
\hline Liquid & 4-allyl-2-methoxyphenol, Balsam resin and water \\
\hline \multicolumn{2}{|l|}{ Sealapex } \\
\hline Base & $\begin{array}{l}\text { N-ethyl toluene solfanamide resin, fumed silica (silicon dioxide), } \\
\text { zinc oxide, calcium oxide }\end{array}$ \\
\hline Catalyst & $\begin{array}{l}\text { Isobutyl salicylate resin, fumed silica (silicon dioxide), bismuth } \\
\text { trioxide, titanium dioxide pigment }\end{array}$ \\
\hline
\end{tabular}

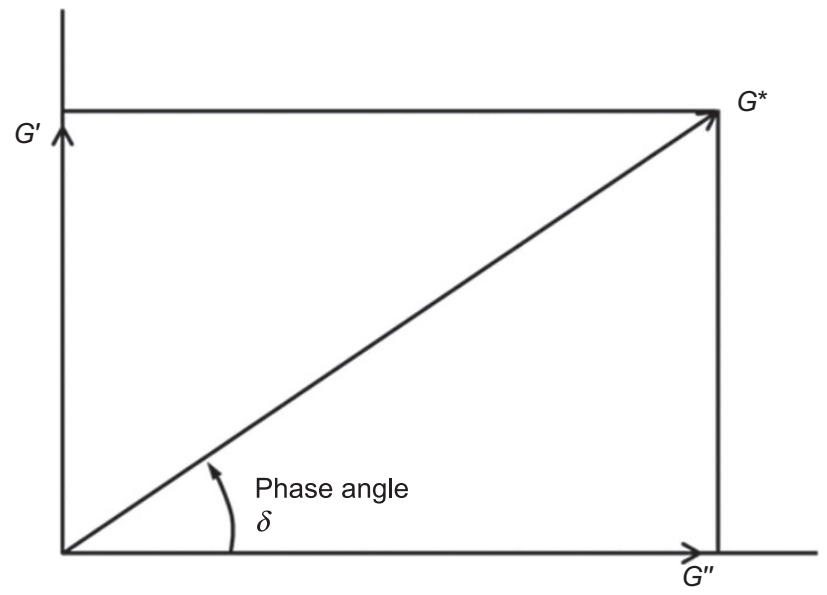

Figure 1 The relationship between $G^{\prime}$ (shear storage modulus) and $G^{\prime \prime}$ (shear loss modulus).

The strain and stress applied to a root canal sealer during oscillatory strain with frequency $\omega$ can be described as follows $\left(\gamma_{0}\right.$ : strain, $\sigma_{0}$ : stress, $t$ : time, $\delta$ : phase angle):

Shear strain $\gamma(t)=\gamma_{0} \sin \omega t$

Shear stress $\sigma(t)=\sigma_{0} \sin (\omega t+\delta)$

From these equations, two moduli can be defined as follows:

$G^{\prime}$ (shear storage modulus $)=\left(\sigma_{0} / \gamma_{0}\right) \cos \delta=G_{0} \cos \delta$

$G^{\prime \prime}$ (shear loss modulus) $=\left(\sigma_{0} / \gamma_{0}\right) \sin \delta=G_{0} \sin \delta$

These equations describe shear strain $\gamma(t)$ and shear stress $\sigma(t)$ and can be alternatively written using complex variables as follows:

Shear strain $\gamma(t)=\gamma_{0} e^{i(\omega t)}$

Shear stress $\sigma(t)=\sigma_{0} e^{i(\omega t+\delta)}$

From these equations, $G^{*}$ (complex shear modulus) can be defined as follows:

$G^{*}=\frac{\sigma(t)}{\gamma(t)}=\frac{\sigma^{0}}{\gamma^{0}} e^{i \delta}=\frac{\sigma^{0}}{\gamma^{0}}(\cos \delta+i \sin \delta)=G^{\prime}+i G^{\prime \prime}$

From this equation, complex viscosity $\left(\eta^{*}\right)$ can be defined as follows: $\eta^{*}=\frac{G^{*}}{\omega}$

$G^{\prime}$ (shear storage modulus) measures the stored energy inside the material, representing the elastic portion, whereas $G^{\prime \prime}$ (shear loss modulus) measures the energy dissipated as heat, representing the viscous portion. ${ }^{27}$ Complex viscosity $\left(\eta^{*}\right)$ measures the resistance of a material to dynamic shear strain.

\section{Measurement of root canal sealer complex viscosities using a dynamic oscillatory shear test}

The rheological properties of the root canal sealers were measured using a strain-controlled rheometer (ARES, Rheometric Scientific, London, UK). First, the samples were mixed and loaded onto the plate at $25{ }^{\circ} \mathrm{C}$, and the chamber was closed to avoid changes in temperature and humidity. A 50-mm cone and plate geometry were used in this study, and the smallest gap between the cone and the plate was $0.05 \mathrm{~mm}$. The complex viscosity value $10 \mathrm{~min}$ after initiating mixing was compared with the flowability measured using the simple press method. Five measurements were made for each root canal sealer. The strain amplitude was $10 \%$, and the angular frequency $(\omega)$ was $5 \mathrm{rad} \cdot \mathrm{s}^{-1}$.

Time-dependent changes in the viscoelasticity of root canal sealers To investigate changes in the rheological properties of root canal sealers over time, a time sweep test was conducted on the four root 
canal sealers at $25{ }^{\circ} \mathrm{C}$. The strain amplitude was $10 \%$, and the angular frequency $(\omega)$ was $5 \mathrm{rad} \cdot \mathrm{s}^{-1}$.

Temperature-dependent changes in the viscoelasticity of root canal sealers

To investigate the changes in the rheological properties of root canal sealers with increasing temperature, a temperature sweep test was performed on the root canal sealers up to $200{ }^{\circ} \mathrm{C}$ at a heating rate of $5{ }^{\circ} \mathrm{C} \cdot \mathrm{min}^{-1}$. The strain amplitude was $10 \%$, and the angular frequency $(\omega)$ was $5 \mathrm{rad} \cdot \mathrm{s}^{-1}$.

Heat flow with increasing temperature measured by differential scanning calorimetry

A differential scanning calorimetry (DSC-Q1000; TA Instruments, New Castle, DE, USA) was used to investigate the change in heat flow in each sample with increasing temperature. Samples weighing $2.5 \mathrm{mg}$ were heated at a rate of $5{ }^{\circ} \mathrm{C} \cdot \mathrm{min}^{-1}$ from 25 to $200{ }^{\circ} \mathrm{C}$, and the heat flows (exothermic or endothermic) of the samples were determined from these measurements. The measurements were conducted in a nitrogenous environment using conventional hermetic aluminium pans.

\section{Statistical analysis}

The correlation between the flowabilities measured using the ISO method and the viscosities measured using the strain-controlled rheometer was evaluated using Spearman's correlation analysis. The differences in the viscosities of the four root canal sealers were analysed statistically using the Kruskal-Wallis test $(\alpha=0.05)$.

\section{RESULTS}

The flowabilities of root canal sealers measured by the ISO method The mean diameters $(n=5)$ of the compressed discs of the root canal sealers are shown in Table 2. The flowability of Pulp Canal Sealer EWT
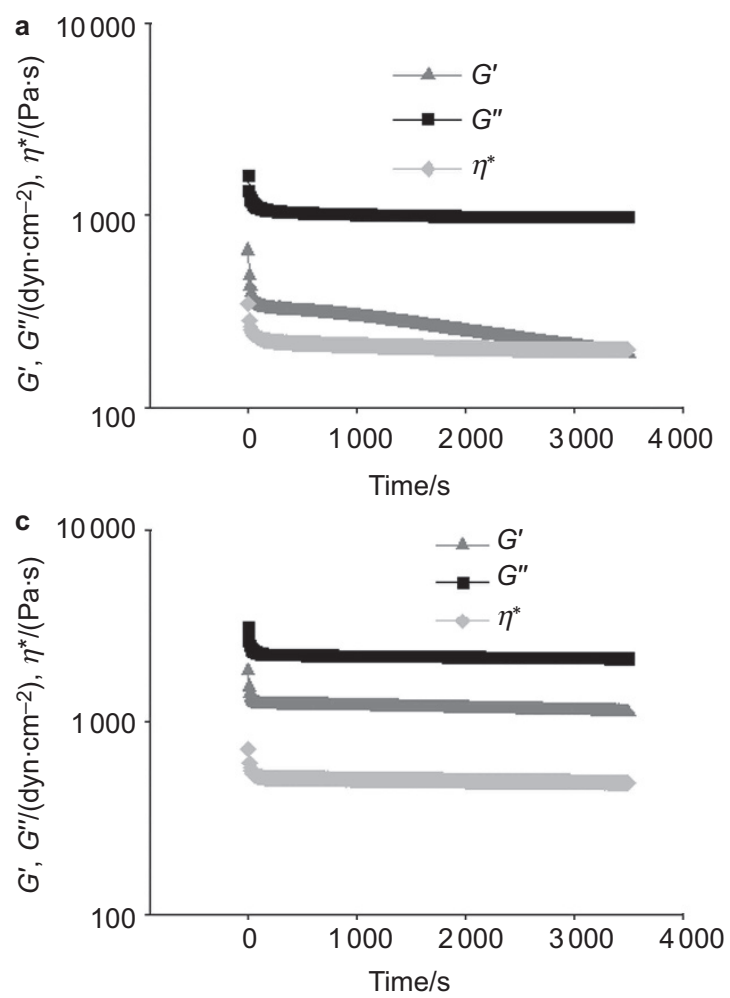

was significantly higher than those of AH Plus, Sealapex and Capseal $(P<0.05)$. The flowabilities of AH Plus and Sealapex showed no significant difference $(P>0.05)$. Capseal showed a lower flowability than $\operatorname{did}$ AH Plus and Sealapex $(P<0.05)$.

Complex viscosities measured by a strain-controlled rheometer The mean complex viscosities were $251.56 \mathrm{~Pa} \cdot \mathrm{s}$ for $\mathrm{AH}$ plus, 4 823.28 Pa·s for Capseal, 523.60 Pa·s for Sealapex and 9.47 Pa·s for Pulp Canal Sealer EWT. The mean complex viscosities were the highest for Pulp Canal Sealer EWT and decreased in the following order: AH Plus $>$ Sealapex $>$ Capseal I $(P<0.05)$. The means and standard deviations of these results are shown in Table 2.

\section{Correlation of the results of the simple press method and the strain-} controlled rheometer

The diameters of the compressed discs measured using the simple press method and the complex viscosities measured using the strain-controlled rheometer showed a strong negative correlation (Spearman's correlation coefficient $\rho=-0.8618, P<0.0001$ ).

\section{Changes in the rheological properties of the root canal sealers with time}

All of the root canal sealers tested showed characteristic changes in their rheological properties with time. AH Plus showed little change in $G^{\prime}, G^{\prime \prime}$ or $\eta^{*}$ (Figure $2 \mathrm{a}$ ). In contrast, Capseal showed a rapid increase in $G^{\prime}, G^{\prime \prime}$ and $\eta^{*}$ during the early period of the setting reaction and eventually reached a plateau (Figure $2 \mathrm{~b}$ ). Sealapex showed little change in $G^{\prime}, G^{\prime}$ and $\eta^{*}$ throughout the experimental period (Figure 2c). The values for $G^{\prime}, G^{\prime \prime}$ and $\eta^{*}$ of Pulp Canal Sealer EWT increased after $2500 \mathrm{~s}$ (Figure $2 \mathrm{~d}$ ).
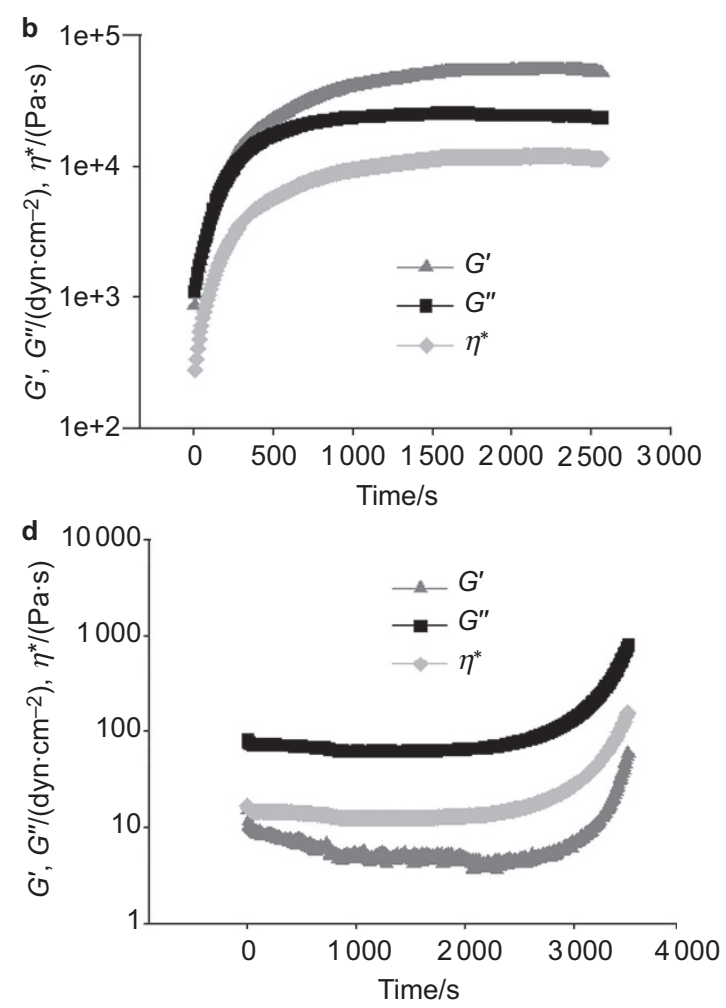

Figure 2 The rheological properties of AH Plus, Capseal, Sealapex and Pulp Canal Sealer EWT showed time-dependent changes. The changes in G', G" and $\delta^{*}$ with time in AH Plus (a), Capseal (b), Sealapex (c) and Pulp Canal Sealer EWT (d) at $25^{\circ} \mathrm{C}$. $G^{\prime}$, shear storage modulus; $G^{\prime \prime}$, shear loss modulus; $\delta^{*}$, complex viscosity. 
Changes in the viscoelasticities of the root canal sealers with increasing temperature

All of the root canal sealers tested showed a change in $\eta^{*}$ with increasing temperature. However, the patterns of change were not identical, and characteristic features were shown based on the material used. $\mathrm{AH}$
Plus showed a valley in complex viscosity at $130{ }^{\circ} \mathrm{C}$ (Figure 3a). Capseal showed a sharp increase in $\eta^{*}$ at temperatures greater than $100{ }^{\circ} \mathrm{C}$ (Figure 3b), while Sealapex showed a large increase in $\eta^{*}$ at temperatures greater than $190{ }^{\circ} \mathrm{C}$ (Figure 3c). Pulp Canal Sealer EWT showed an increased peak in $\eta^{*}$ at $80-130{ }^{\circ} \mathrm{C}$ (Figure $3 \mathrm{~d}$ ).

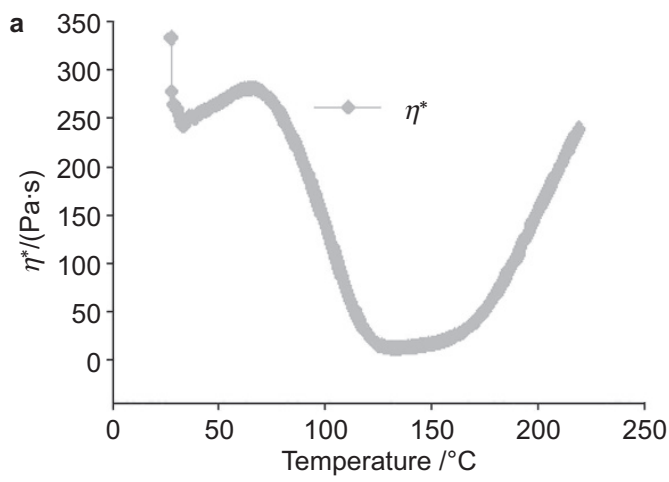

b
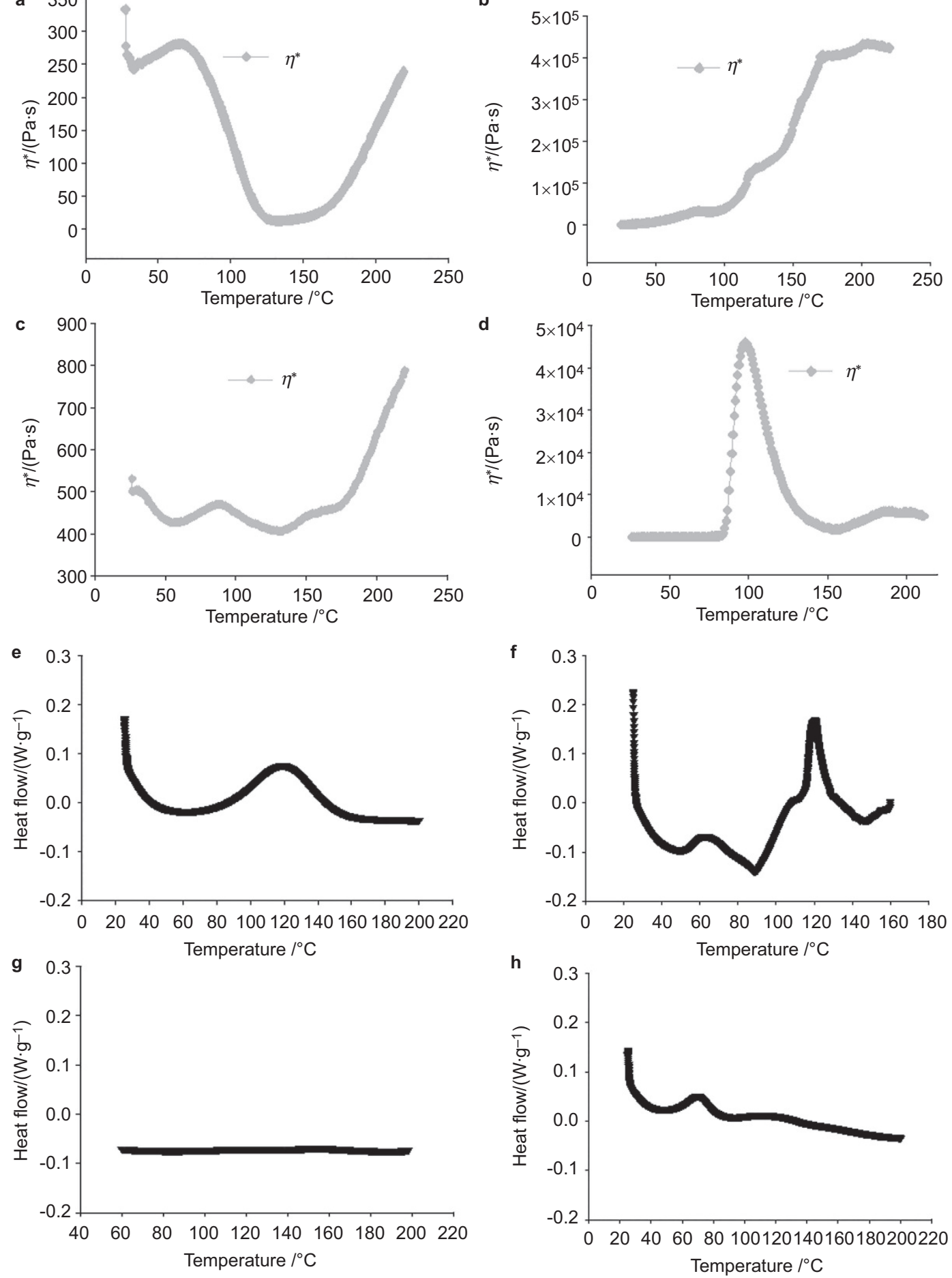

Figure 3 The rheological properties of AH Plus, Capseal, Sealapex and Pulp Canal Sealer EWT showed temperature-dependent changes. These four root canal sealers showed different patterns of heat flow with increasing temperature, as determined by DSC. The change in $\eta^{*}$ with increasing temperature in AH Plus (a), Capseal (b), Sealapex (c) and Pulp Canal Sealer EWT (d). The heat flow induced by increasing temperature in AH Plus (e), Capseal (f), Sealapex (g) and Pulp Canal Sealer EWT (h). DSC, differential scanning calorimetry; $\eta^{*}$ : complex viscosity. 
Table 2 Flowabilities measured by simple press method (ISO 6876) $(n=5)$ and complex viscosities measured by strain-controlled rheometer $(n=5)$ (mean \pm standard deviation)

\begin{tabular}{|c|c|c|c|c|c|}
\hline Root canal sealers & AH Plus & Capseal I & Pulp Canal Sealer EWT & Sealapex & $P$ value \\
\hline Disc diameter/mm & $22.6 \pm 0.55^{b}$ & $20.4 \pm 0.55^{a}$ & $31.2 \pm 0.55^{c}$ & $22.4 \pm 0.84^{b}$ & 0.01 \\
\hline Complex viscosity/(Pa.s) & $251.56 \pm 35.34^{b}$ & $4823.28 \pm 1220.65^{d}$ & $9.47 \pm 4.19^{a}$ & $523.60 \pm 20.73^{c}$ & $<0.001$ \\
\hline
\end{tabular}

ISO, International Organization for Standardization.

Same superscript within the same column represents no statistically significant difference, $\alpha<0.05$.

\section{Heat flow with increasing temperature measured by DSC}

All root canal sealers showed characteristic exothermic or endothermic peaks. Exothermic peaks occurred at $119.4{ }^{\circ} \mathrm{C}$ for AH Plus (Figure 3e), $112.5{ }^{\circ} \mathrm{C}$ for Capseal (Figure 3 ) and $70.3{ }^{\circ} \mathrm{C}$ for Pulp Canal Sealer EWT (Figure 3h). Endothermic peaks occurred at $63.0{ }^{\circ} \mathrm{C}$ for AH Plus (Figure 3e), $92.1{ }^{\circ} \mathrm{C}$ and $137.4{ }^{\circ} \mathrm{C}$ for Capseal (Figure $3 \mathrm{f}$ ) and $92.2{ }^{\circ} \mathrm{C}$ for Pulp Canal Sealer EWT (Figure $3 \mathrm{~h}$ ). Sealapex showed no marked exothermic or endothermic peaks (Figure $3 \mathrm{~g}$ ).

\section{DISCUSSION}

Most previous studies ${ }^{10-17}$ on the flowabilities of root canal sealers used the simple press method, which provides limited information. Recently, Lacey et al. ${ }^{18}$ used a custom-made capillary rheometer to investigate the volume and rate of flow of root canal sealers. Although this is clinically relevant information, this study did not provide the viscosity values for the root canal sealers or data regarding the rheological properties of the root canal sealers as a function of time or temperature. To overcome the shortcomings of the simple press method, a strain-controlled rheometer, which has been widely used to measure the viscoelastic properties of dental composites ${ }^{28-31}$ and impression materials, ${ }^{32}$ was used in this study. The results showed that the flowability of root canal sealers measured using the simple press method and the complex viscosities measured using the strain-controlled rheometer were closely correlated. Thus, the null hypothesis was rejected. Notably, the flow diameters of AH Plus $(22.6 \mathrm{~mm})$ and Sealapex $(22.4 \mathrm{~mm})$ were not significantly different, whereas the complex viscosities of AH Plus (251.56 Pa·s) and Sealapex (523.60 Pa.s) were significantly different. These results suggest that the strain-controlled rheometer is more sensitive than the simple press method for measuring the rheological properties of root canal sealers.

Almeida et al. ${ }^{13}$ compared the flowabilities of root canal sealers using the simple press method and reported that the flowability was highest for Pulp Canal Sealer EWT, intermediate for AH Plus and lowest for Sealapex. These results agreed well with the results of the present study. The high flowability of Pulp Canal Sealer EWT may be due to the resin additives. ${ }^{13,33}$

Regarding the time-dependent changes in the rheological properties of the root canal sealers, AH Plus showed little change in complex viscosity with time. This result supports a report that the working time for AH Plus is 4 h. ${ }^{34}$ Capseal showed an early increase in complex viscosity, which could be explained by an early setting reaction that occurs between dicalcium phosphate dihydrate and tetracalcium phosphate. These results agree with those of a previous study ${ }^{35}$ that reported that the setting time of calcium phosphate ranged from 30 to 60 min. ${ }^{36}$ Sealapex showed little change in complex viscosity during the study. This result agreed with those of previous studies reporting that Sealapex sets in 2-3 weeks in 100\% relative humidity and does not set in a dry environment. ${ }^{36-38}$

A temperature sweep test and DSC analysis were carried out to investigate the rheological and thermal changes induced in root canal sealers by increasing temperature. In the temperature sweep test, $\mathrm{AH}$
Plus showed a valley in complex viscosity at approximately $130{ }^{\circ} \mathrm{C}$ (Figure 3a). This temperature was close to that at which AH Plus showed an exothermic peak $\left(119.4{ }^{\circ} \mathrm{C}\right)$ (Figure 3e). Considering that exothermic or endothermic peaks indicate the temperature at which some chemical reactions occur, this phenomenon suggests that $\mathrm{AH}$ Plus undergoes a chemical change at approximately $120-130{ }^{\circ} \mathrm{C}$. However, the exact nature and underlying mechanism of this change remain unclear, which could be considered a limitation of this study. Thus, future studies are necessary to investigate the nature of this chemical change. Capseal showed an increase in complex viscosity at 100-140 ${ }^{\circ} \mathrm{C}$ (Figure 3b). In the DSC analysis, Capseal had an exothermic peak at $112.5{ }^{\circ} \mathrm{C}$ (Figure 3f), which suggests that Capseal might undergo a chemical change at $100-120{ }^{\circ} \mathrm{C}$. The nature of this chemical change must also be addressed in future studies. In contrast, Sealapex showed no exothermic or endothermic peaks in the DSC analysis, which suggests that increased temperature does not induce significant chemical changes in Sealapex.

The clinical significance of this study is first that Pulp Canal Sealer EWT showed the lowest viscosity of the four tested sealers, suggesting that Pulp Canal Sealer has the best flowability in clinical application. Second, Capseal showed a rapid increase in viscosity with increasing time, which suggests that Capseal has a shorter working time than $\mathrm{AH}$ Plus, Sealapex, and Pulp Canal Sealer EWT. Third, an increased temperature induces chemical changes in $\mathrm{AH}$ Plus and Capseal but not in Sealapex.

\section{CONCLUSION}

This study showed that a strain-controlled rheometer can measure the rheological properties of root canal sealers more sensitively than the simple press method can. Four root canal sealers showed typical timeand temperature-dependent changes in their rheological properties.

\section{ACKNOWLEDGEMENTS}

This research was supported by the Basic Science Research Program through the National Research Foundation of Korea (NRF) funded by the Ministry of Science, ICT and Future Planning (2011-0014231). This study was supported by the National Research Foundation of Korea funded by Ministry of Education, Science and Technology (2009-0086835). This study was supported by a grant from the Kyung Hee University in 2013 (KHU-20131045). This study was supported by Grant No. 04-2009-0032 from the SNUDH Research Fund.

1 Brothman P. A comparative study of the vertical and the lateral condensation of guttapercha. J Endod 1981; 7(1): 27-30.

2 Lee BS, Wang CY, Fang YY et al. A novel urethane acrylate-based root canal sealer with improved degree of conversion, cytotoxicity, bond strengths, solubility, and dimensional stability. J Endod 2011; 37(2): 246-249.

3 Kontakiotis EG, Tzanetakis GN, Loizides AL. A comparative study of contact angles of four different root canal sealers. J Endod 2007; 33(3): 299-302.

4 Ersahan S, Aydin C. Dislocation resistance of iRoot SP, a calcium silicate-based sealer, from radicular dentine. J Endod 2010; 36(12): 2000-2002.

5 Balguerie $\mathrm{E}$, van der Sluis $\mathrm{L}$, Vallaeys $\mathrm{K}$ et al. Sealer penetration and adaptation in the dentinal tubules: a scanning electron microscopic study. J Endod 2011; 37(11): $1576-1579$. 
6 Loushine BA, Bryan TE, Looney SW et al. Setting properties and cytotoxicity evaluation of a premixed bioceramic root canal sealer. J Endod 2011; 37(5): 673677.

7 Nawal RR, Parande M, Sehgal R et al. A comparative evaluation of antimicrobia efficacy and flow properties for Epiphany, Guttaflow and AH-Plus sealer. Int Endod J 2011; 44(4): 307-313.

8 Marin-Bauza GA, Rached-Junior FJ, Souza-Gabriel AE et al. Physicochemical properties of methacrylate resin-based root canal sealers. J Endod 2010; 36(9): 1531-1536.

9 Siqueira JF Jr, Favieri A, Gahyva SM et al. Antimicrobial activity and flow rate of newer and established root canal sealers. J Endod 2000; 26(5): 274-277.

10 Baldi JV, Bernardes RA, Duarte MA et al. Variability of physicochemical properties of an epoxy resin sealer taken from different parts of the same tube. Int Endod J 2012; 45(10): 915-920.

11 Kuga MC, Faria G, So MV et al. The impact of the addition of iodoform on the physicochemical properties of an epoxy-based endodontic sealer. J Appl Oral Sci 2014; 22(2): 125-130.

12 Tanomaru-Filho M, Bosso R, Viapiana R et al. Radiopacity and flow of differen endodontic sealers. Acta Odontol Latinoam 2013; 26(2): 121-125.

13 Almeida JF, Gomes BP, Ferraz CC et al. Filling of artificial lateral canals and microleakage and flow of five endodontic sealers. Int Endod J 2007; 40(9): 692-699.

14 Gambarini G, Testarelli L, Pongione G et al. Radiographic and rheological properties of a new endodontic sealer. Aust Endod J 2006; 32(1): 31-34.

15 Fonzi M, Fonzi L, Lungarella $\mathrm{G}$ et al. [Biocompatibility and physico-mechanical properties of the new Venezia root canal sealer. In vivo and In vivo test according international standards]. Minerva Stomato/ 2001; 50(3/4): 91-100. Italian.

16 Siqueira FJ Jr, Fraga RC, Garcia PF. Evaluation of sealing ability, $\mathrm{pH}$ and flow rate of three calcium hydroxide-based sealers. Endod Dent Traumato/ 1995; 11(5): 225-228.

17 Ono K, Matsumoto K. Physical properties of $\mathrm{CH} 61$, a newly developed root canal sealer. J Endod 1998; 24(4): 244-247.

18 Lacey S, Pitt Ford TR, Watson TF et al. A study of the rheological properties of endodontic sealers. Int Endod J 2005; 38(8): 499-504.

19 Lacey S, Pitt Ford TR, Yuan XF et al. The effect of temperature on viscosity of root canal sealers. Int Endod J 2006; 39(11): 860-866.

20 International Standardization Organization. ISO 6876: dental root canal sealing materials. Geneva: International Standardization Organization, 2001.

21 Kaplan AE, Ormaechea MF, Picca M etal. Rheological properties and biocompatibility of endodontic sealers. Int Endod J 2003; 36(8): 527-532.

22 Barnes HA, Hutton JF, Walters K. Rheology of polymeric liquids. Introduction to rheology. Amsterdam: Elsevier, 2001.

23 Bae KH, Chang SW, Bae KS et al. Evaluation of $\mathrm{pH}$ and calcium ion release in capseal and II and in two other root canal sealers. Oral Surg Oral Med Oral Pathol Oral Radiol Endod 2011; 112(5): e23-e28.
24 Yang SE, Baek SH, Lee $W$ et al. In vitro evaluation of the sealing ability of newly developed calcium phosphate-based root canal sealer. J Endod 2007; 33(8): 978-981.

$25 \mathrm{Kim}$ JS, Baek SH, Bae KS. In vivo study on the biocompatibility of newly developed calcium phosphate-based root canal sealers. J Endod 2004; 30(10): 708-711.

26 Bae WJ, Chang SW, Lee SI et al. Human periodontal ligament cell response to a newly developed calcium phosphate-based root canal sealer. J Endod 2010; 36(10): 16581663.

27 Lee IB, Son HH, Um CM. Rheologic properties of flowable, conventional hybrid, and condensable composite resins. Dent Mater 2003; 19(4): 298-307.

28 Ellakwa A, Cho N, Lee IB. The effect of resin matrix composition on the polymerization shrinkage and rheological properties of experimental dental composites. Dent Mater 2007; 23(10): 1229-1235.

29 Lee IB, Min SH, Kim SY et al. Slumping tendency and rheological properties of flowable composites. Dent Mater 2010; 26(5): 443-448.

$30 \mathrm{Kim} \mathrm{MH}$, Min SH, Ferracane J et al. Initial dynamic viscoelasticity change of composites during light curing. Dent Mater 2010; 26(5): 463-470.

31 Beun S, Bailly C, Dabin A et al. Rheological properties of experimental Bis-GMA TEGDMA flowable resin composites with various macrofiller/microfiller ratio. Dent Mater 2009; 25(2): 198-205.

32 German MJ, Carrick TE, McCabe JF. Surface detail reproduction of elastomeric impression materials related to rheological properties. Dent Mater 2008; 24(7): 951-956.

33 Grossman LI. The effect of $\mathrm{pH}$ of rosin on setting time of root canal cements. J Endod 1982; 8(7): 326-327.

34 Ingle JI, Bakland LK, Baumgartner JC. Ingle's endodontics. 6 ed. Lewiston: BC Decker, 2008

35 Miyamoto $\mathrm{Y}$, Ishikawa $\mathrm{K}$, Takechi $\mathrm{M}$ et al. Tissue response to fast-setting calcium phosphate cement in bone. J Biomed Mater Res 1997; 37(4): 457-464.

36 Caicedo R, von Fraunhofer JA. The properties of endodontic sealer cements. J Endod 1988; 14(11): 527-534.

37 Allan NA, Walton RC, Schaeffer MA et al. Setting times for endodontic sealers under clinical usage and in vitro conditions. J Endod 2001; 27(6): 421-423.

38 Desai S, Chandler N. Calcium hydroxide-based root canal sealers: a review. J Endod 2009; 35(4): 475-480.

(c) (i) $\Theta$ This work is licensed under a Creative Commons Attribution(c) party material in this article are included in the article's Creative Commons license, unless indicated otherwise in the credit line; if the material is not included under the Creative Commons license, users will need to obtain permission from the license holder to reproduce the material. To view a copy of this license, visit http://creativecommons.org/licenses/ by-nc-nd/3.0/ 